DOI: $10.1515 /$ hssr -2015-0012

\title{
Ştefan Aug. Doinaş and Basarab Nicolescu, Epistolary Exchange and Aesthetic Transfiguration of Certain Transdisciplinary Concepts
}

\author{
Maria Chețan * \\ „Unirea” National College of Târgu Mureș, Romania
}

\begin{abstract}
Ştefan Aug. Doinaş and Basarab Nicolescu, two great spirits related through the generosity of the humanist vision, met, held an epistolary dialogue and had common projects. Doinaş commented upon a few of the innovative concepts proposed by Basarab Nicolescu and he also aesthetically transfigured, in literary pages, certain concepts of transdisciplinarity.
\end{abstract}

Keywords:

Epistolary dialogue, Transdisciplinarity, Prose, Aesthetic transfiguration.

Ştefan Aug. Doinaş met Franco-Romanian philosopher and physicist Basarab Nicolescu at a conference about transdisciplinarity, the latter supported by the New Europe College (NEC), on 19 November 1998. Doinass was sitting in the first row, listening carefully (a proof of the writer's interest in this issue is the fact that a few months before the conference that he was attending at NEC, he had written, a welldocumented article about The Transdisciplinarity Manifesto, published in The Current on 4 June 1998).

However, the writers' epistolary relationship preceded this event, and

\footnotetext{
* „Unirea” National College of Târgu Mureş, Str. Mihai Viteazul nr. 17, Târgu Mureş, marianachetan@yahoo.com
} 
it had previously enjoyed a longer evolution.

From the correspondence that has been made available courtesy of the transdisciplinarity founder, there is a letter dated 8 September 1997, through which the editor-in-chief of "20th Century" communicates to Basarab Nicolescu that towards the end of the year, the publication he was running intended to have an edition on the topic of "exile", and the rubric "20 towards 21" was going to be dedicated to the texts by Stéphane Lupasco in „3e Millenaire”. Thanking at the same time for copies of the magazine " $3 \mathrm{e}$ Millenaire" (courtesy of Mr Solomon Marcus), Doinaş requested Basarab Nicolescu's agreement for the publication of all texts authoredby Stéphane Lupasco, the "21st Century" Foundation intending to get the most of those articles by publishing them in a standalone bilingual volume. Doinaş invited Basarab Nicolescu to write a foreword to the pages by Stéphane Lupasco, and thus introduce the " 3 e Millenaire" journal to the Romanian public.

In his response (letter dated 27 September 1997, Paris), Basarab Nicolescu states that he had sent the required works a week before, which contained the texts by Lupaşcu, and the prefatory text depended on the time allowed by the Romanian journal. The correspondence between the two writers on the subject continues, Doinaş proposing a deadline on 20 November, even though the collection of texts on exile ends in late October. Another letter (sent by fax, dated 14 October 1997) acknowledges receipt of the magazines sent from Paris, asking for confirmation that the numbers 2, 4, 6, 7 of "3e Millenaire" are the only ones signed by Stefan Lupaşcu.

Some explanations by Basarab Nicolescu (letter dated 15 October 1997, Paris) state that the copyright of Lupasco's works belongs to his daughter, Alde Lupasco, and Nicolescu commits to writing a preface for the volume. Herein we also find explanations on the first edition of " $3 \mathrm{e}$ Millenaire" which was initially published between 1982 and 1985, and sold about 11,000 copies, but when it reached its $21^{\text {st }}$ edition and the manager intended to triple the circulation, it went bankrupt: "The title is sold for 1,000 francs. The magazine will go on with the same title but with a totally different staff and a different management team" (Basarab Nicolescu, Letter to Ştefan Aug. Doinaş, 15 October 1997, Paris).

A Lupasco colloquium was set for 13 March 1998, organised by the 
Romanian Cultural Centre and CIRET, where Doinaş was an honorary guest. At the beginning of the year however (in a fax dated 20 January 1998 addressed to Mr. Horia Bădescu, director of the Romanian Cultural Centre in Paris), the Romanian writer points out that an extended convalescence, after two months of hospitalisation, will prevent him from honouring the invitation, but asks that the assisting chief editor of the "20 th Century" journal, director of the Foundation, Miss Alina Ledeanu attend the colloquium, present the latest edition of the journal and maybe even obtain other prestigious testimonials to be included in the upcoming volume dedicated to Lupasco.

Adding to the letter (8 June 1998) a text about transdisciplinarity, Doinass acknowledges Basarab Nicolescu's contribution to making possible the appearance of " $20^{\text {th }}$ Century" in the Parisian colloquium, while congratulating him for the success of the event. Other issues raised in the letter refer to the planned Lupasco volume: the summary idea proposed by the French philosopher and physicist is approved, Doinass counting on a substantial preface from the latter and stating that the volume would appear next year, and that they should both take part in its release. Another aspect to which Doinass points out and particularly enjoys is the idea (seen as "formidable") of a Valéry-Lupasco colloquium, brought forward by Alina Ledeanu and Basarab Nicolescu.

The "20th Century" journal (no. 10-12 / 1997, 1-3 / 1998) publishes a consistent selection of articles by Stéphane Lupasco: the articles "For a necessary mutation in the logic of the intellect", "The sociologic energy", "Acknowledging knowledge or my brain as a laboratory", "Systemology and structorology", never before published together in a volume. They were prefaced by Solomon Marcus and Ilie Pârvu. These works were part of the last published texts by the philosopher (translated by Laurențiu Staicu). The other planned actions will not have the same fate though: the volume that was to contain texts by Stéphane Lupasco will no longer see the light of day, and neither will the Valéry-Lupasco colloquium.

Proof of the preoccupations generated by the innovative ideas of transdisciplinarity is the article "What is transdisciplinarity?" (Doinaş, 1998), in which Ştefan Aug. Doinaş traces the lines of a portrait of Basarab Nicolescu, presenting him as a man of culture whose 
predecessors are Jean Piaget, Edgar Morin and Erich Jantsch. The man that had launched the term "Transdisciplinarity" is portrayed as a particularly active person (organizer, among others, of the 1998 Stéphane Lupasco International Colloquium, being a close friend of the Romanian-born philosopher honoured by the aforementioned manifestation). The most beautiful appreciation, which equally highlights his capacity for synthesis and art of portraiture, is found in a phrase situated towards the end of the article: "Basarab Nicolescu is a complex spirit, mastering both the rigour of a scientist and the momentum of an explorer of the human imaginary" (Doinaş, 1998: 23).

Concerned in particular with the "Charter of Transdisciplinarity", Doinaş lists the most important articles, highlighting the harmonious manner in which the former conjugates sciences and humanities, as well as another aspect, related to the creation of a new horizon, able to bring together disciplines, while at the same time surpassing them: "Open to myth and religion without a prime decree or law to judge other cultures, transdisciplinarity reassesses the role of intuition, imagination, sensitivity and the body. Economy must serve mankind, and not the other way round. Transdisciplinarity ethics recuses any refusal of dialogue. Otherness must be respected: rigour (in the argumentation), openness (by accepting the unknown, the unpredictable) and tolerance (right to ideas and truths opposed to ours)" (Doinaş, 1998: 23).

The fortunate meeting between Doinass and Basarab Nicolescu left its marks. It is not just about the exchange of letters which reveals common preoccupations, but also about the way in which transdisciplinarity concepts, known and analysed by Doinass in the above-mentioned article, are creatively valorised by the latter into a strikingly peculiar literature.

In May 2002, a slightly odd text is published in the journal "The Family", entitled "Kilometre zero", with the final words "Excerpt from the novel entitled - provisionally - Intersection". The text is accompanied by explanations of the deputy chief editor, Dumitru Chirilă, showing that the collection published in the month of the poet's death encompassed various creations, from poetry to prose and essays, and the author himself indicated the order in which the texts had to be arranged. A plea for the veracity of the issues presented in his writing is the beginning of chapter $\mathrm{V}$, which continues with some considerations about reality and 
Levels of Reality. Fragments are inserted, which deal with "little reason", "saint ternary", "miracle", issues that enable statements about horizontal existence, which cannot pull us out of the "impasse of a single ontological horizon in which we are more vegetative than alive" They also deal with the layering of horizons, each horizon representing the hyphen between two levels, where characters and events moving about invade the horizons above and beneath.

To the incipit "But do you know how many levels of Reality exist?" (Doinaş year 38 (138), 22) comes the symmetrical and rounded answerin the last statement of the text: "Reality is arborescent" (Doinaş year 38 (138), 33). This general statement is detailed and supported by two previous poetic images, that of an extremely tall tower from which on certain levels balconies and doors open, each level offering the possibility of another existence, the necessary space for such an existence being created as one advances, on the principle of an escalator, as well as that of a tree: "From every knot of vertical Reality, just like from every knot of a giant tree with a massive canopy, a side branch detaches, a leaf area appears, and these new horizontal availabilities ensure the new space for the author's new fictive creations" (Doinaş year 38 (138), 33).

The two concept images created by Doinaş, the tower and the tree, act as two poetic responses to certain gradually introduced philosophemes. Firstly, the hourglass image from which sand constantly flows, serves to highlight the complex structure of the real-fictional relationship. This report, found only in the literary work, prefigures the shift towards the ontological, because "actual events" and "characters" destiny" are parts of an existential adventure: "As long as we remain in what is called real - which, in its essence is merely a level of Reality - we cannot see what happens beyond it. But as soon as we flip the object, we realise that between this level of Reality - which we call it - and the other levels, there is an intimate rapport which only now becomes apparent, visible, in such a way that the things "from below", as well as those "from above" - both of same value - gain the same certificate of existence, of vitality, as the ones on our level, the only one which - we, commoners - are able to perceive" (Doinass year 38 (138), 32). An argument of the communication between horizons is also found - as shown by Doinaş - in the Romanian folklore, which emphasises the 
rapture between worlds, but at the same time states the possibility of a relationship as Prince Charming passes between them: the descent of the hero into the "other realm" asserts the existence of a "subterranean of miracles" which is omnipresent in our tales.

Built as an argument, a theoretical scaffolding for the epic matter of the previous chapters, part no. $\mathrm{V}$ provides evidence supplied by the modern philosophical approach to the task at hand. Doinass introduces statements by a "Romanian thinker, a refugee in France", without naming anyone, probably considering the supplied clues to be more than sufficient.

The inserted expressions ("the short reason", "ternary saint", "classical binary contradiction" which must become ternary, "levels of Reality", etc.) are concepts conveyed by the physicist and essayist Basarab Nicolescu, and some theorems are references to the same author. The arguments invoked by Doinass in this chapter of "Kilometre zero" may either be from the area of the collective mind (whose expression is materialized in the referred Romanian tales), or the creation of a modern thinker such as Basarab Nicolescu; they converge towards accrediting a common idea, that reality is multi-storied, and there is communication between its levels. This is exactly what the characters of this prose experience, a writer and the fictions he creates. Basarab Nicolescu's poetic theorems, through which multiple aspects of the novel fragment can be understood (otherwise demonstrated by repeatedly quoting phrases or sentences belonging to the Romanian essayist and physicist), provides a special magnitude and interpretative opening to the text.

In the first chapter, the one that takes the "step" from one level to the other, is a character from another story by Doinaş ("The visit of the personal star"): Roni Margulia. "The paper being" does not trace Augusto's gesture from The Fog by Unamuno, in the sense that it does not come to meet its creator, but rather provokes it, by meeting only its brother. The author's monologue "decrypts" the mechanism by which the transition is made from Basarab Nicolescu's concepts to the literary text, adding an expressionist suggestion as well: "Could there be an excess of vitality in certain characters, which won't be exclusively consumed in the text's dimension, but rather "pour over", just like Dali's 
clock, over the edge of a certain reality? [...] And if they were to truly become «real», on how many levels could they be efficient?" (Doinaş year 38 (138), 24).

A different kind of border crossing configures the second chapter, the one in which the public Symai bath is presented where, coming from a distance of over 50 years, the author-character would repeat the act of creation, experimenting with the "corporealization" of a being, conferring concrete traits to the yet unclear silhouette which, just like any character, once defined, becomes free, warning its creator not to try and test its consistency, stating that they will meet again in unforeseen circumstances (one way of highlighting the disappearance of the ubiquitous writer and stating the almost equal status between the created and the creator).

Another situation of level transcendence seems to be suggested by the dream episode which the storyteller of "Kilometre zero" experiences, referring to Greg Majaru's persona, a former friend of his. The existential level on which it is placed is the dream one, an area which emits troubling signals towards what we call "reality". Though as long as the postulates put forward by Basarab Nicolescu are accepted, those according to which "the levels of Reality are energetic levels" (Nicolescu, 2007: 21) and "there are as many levels of perception as there are of Reality" (Nicolescu, 2007: 25), the narrator's anxiety from "Kilometre zero" may get unexpected connotations, two-way communication being possible (signals coming from the dream to the real world, but going the other way as well), confessing all about the mysterious passage between the different levels. As a sort of crescendo, in chapter IV, the narrator's unrest is generated by suggesting an unexpected possibility, that of its own uncertain ontological status: "Do you know, he asked me with unflinching irony, that you are the main character, which enunciates in the first person, of a story fabled by... someone else?” (Doinaş year 38 (138), 31)

If we were to synthesize the contexts of producing the communication between the levels of reality presented by Doinaş in "Kilometre zero", we can see the character emerging from the book and entering the real world, then transitioning into being, transmitting information to and from the realm of dreams, and finally a warning to 
the writer that he himself lives in a fiction that is someone else's work. These are in fact, multiple ways of artistic illustration of the concepts conveyed by Basarab Nicolescu, but at the same time a realization of how the mixed discourse theorized by the homonymous writer can work in Doinaş' prose .

The character Cicerone Margulia represents a connection between the novel fragment "Kilometre zero" and the short story "The visit of the personal star". Set by the narrator from the beginning under a mythological sign "Anytime Roni Margulia was mentioned, inevitably there was talk about the intermediary heaven..." (Doinaş, 2000: 188), the less than likely history of this man must first be "accredited". To this end, the narrator's voice seems impersonal at first and it expresses opinions of the collective: "there was talk of", "was unknown", and "everyone was certain of". The idea on whose verisimilitude the narrator insists is that of the intermediary heaven, a notion which he has the ability to convey as being put forth by the other people. To increase the robustness of the edifice, the narrator brings metatextual appreciations and cultural information: "The image was not quite new; it merely supplied a new frame to the ancient Greek beliefs, according to which the demonic is an impersonal force, lingering between humans and gods; the famous Socrates' daimon is said to have come from this area" (Doinaş, 2000: 188).

The appeal to Greek mythology somehow validates the claim concerning the intermediate heaven, by arguing the existence of a long tradition of belief in the demonic. The reference to Socrates and his good daimon also points to the history of humanity, inscribing somewhat the situation to be recounted in a long series of human acts or maybe, to a limited extent, just as for the Greek philosopher, the personal daimon became a ground for accusation under the pretext that he no longer respects the gods of the citadel and favours new gods, this aspect, like a mise en abîme, would become representative for Roni Margulia, whose protective personal star will eventually turn against him.

As for the others, a fascinating personality, Margulia succeeds in everything, effortlessly (he receives a diplomatic post, buys a yacht, is elected president of GM, joins the Academy, etc.). The mystery surrounding him is maintained by a special relationship with his personal 
star, a connection he is not shy to display, casually treating people's curiosity and even saying that he is the centre of the stars' attention and not vice versa. He chooses a wife named Stela, names his son Stelian, has his villa guarded by five dogs, each bearing a star on its forehead, and in the study room ten volumes of the same theme are visible: a snowflakeshaped star.

The inextricable mix of free will and predetermination in Margulia's life receives new meanings if we are to look at it with the same meaning given to the demonic by Ştefan Aug. Doinaş in his essay "Tragic and demonic". Indifferent to ethical problems, consisting of positive and negative elements, the demonic implies a certain ambiguity of actions, requiring the continuous presence of paradox. Genius is understood as a general symptom of the demonic, and in the case of men of action, an entire suite of gestures and decisions exists, which seems to be sustained from the outside by a supernatural force. The composition of the demonic phenomenon is considered more complex than the religious interpretation suggests, requiring, alongside negative traits (pointing to the satanic) positive ones as well.

The demonic man advances through life with a kind of feverishness, driven by his own internal combustion, and the moment his mission is accomplished coincides with the one he is ready for departure, becoming completely detached from this world. To someone unimplicated, to an external observer, the phenomenon is presented as the flipside of the coin, causing all things to tangle. If for the common folk unexpected death is merely bad luck, a fatality, for the demonic man the situation is completely different: "the death of a certain personality is no accident: it has been foretold countless times in numerous acts of bravery which have led the man to the top. More befitting would rather be the surprise of the delay with which the fall, continuously risked and invoked, takes place" (Doinaş, 1980: 478).

To the physical phenomenon of the violent death of this world corresponds, at another level, the end of mysterious help and the disfavouring of demons. In a way, the disappearance of the demonic man means a return to the usual frames, since his birth was an exception, a deviation from the norm: "The demonic breaks the temporal flux" (Doinaş, 1980: 479). The death of the demonic man, regardless of 
whether he brings along revolution, crime, masterpiece or adventure, eliminates the exception and gives time back its usual flow.

The features that make up the theoretical profile of the demonic man can largely be found in Roni Margulia, who seems to fit the mould created by his own author decades ago. Skilfully dosing the ambiguity of perception ("One might have the impression that...") the narrator highlights the supernatural aid the protagonist receives from superior forces: "The connection to the stars is uncontested by anyone though" (Doinaş, 2000: 190), because the situation is always modified by an imponderable element, as a coup de theatre, "an unseen hand" governing its destiny. The radiance of the demonic man is found in Margulia's acts "The sudden glow of his success" (Doinass, 2000: 190), the latter being a person who succeeds even though, realistically, his rival is better in every way (as proved by the way he is accepted into the Academy) or even when he is, apparently, chanceless (being elected as CEO of GM).

Fully aware that some higher forces will decide the moment of his withdrawal from the stage of life where he merely walks a prewritten path, Margulia takes his old school mate as his defender, but merely as a gesture of reverence and recognition of a final that concludes an exceptional existence. The child that helped Margulia for the first time in his life is now his defence lawyer. That boy played the part of "the grain of sand in the shell" (Doinaş, 1980: 476), of the initial element creating the fulminating career of Roni is once again by his side, and the circle of life is complete.

The final victory at the trial is one à la Pyrrhus, an extremely costly one. Two months later signs of decline are present: the giant Vega is poisoned, Stela dies in an accident and Stelian is injured. Roni Margulia himself is found dead, empowering none other than the narrator as a legal guardian of his son and administrator of his wealth, merely the day before his death. No detail is offered to the reader about the businessman's death, insisting though on the fact that he knew when and where it was going to happen.

The destiny of the demonic man is illustrated wholly through this character, whose exceptional path, just as his surprising death, were decided on another level than the human one. The demons of the intermediary heaven have decided on its thundering trajectory but also 
decline, the accident of his birth abruptly erased, the continuous stream of time resuming its usual flow. A transgression of cultural philosophical concepts in the literary work "The visit of the personal star" represents a metatext in the sense that a first class text ("Tragic and demonic") represents the base for a second class (the literary one), the latter revealing its connotations by constantly referring to the concepts presented in the primary source, the scholarly influence coming from Doinaş the philosopher going towards Doinaş the writer.

Literary works by Doinaş which reflect concerns about the artistic transfigurations of concepts with which transdisciplinarity currently operates were also published before the author had the epistolary exchange with Basarab Nicolescu, or before the aforementioned article was published in The Current. Illustrative examples of this idea are "Dialogue with a topographer", "The third dimension" (which, when published in "T from Treasure," appears with the changed title "Plane existence") or "The stone dog", published in 1983 in the "Literary almanac".

The character that gives the prose "Dialogue with a topographer" its title is mentioned in another literary work as well; just as in Roni Margulia's case, the author himself makes a connection revealed only by a careful reading: the "topographer" is also mentioned in "Kilometre zero" (Doinaş year 38 (138), 30), where transdisciplinarity concepts are explicitly inserted by the author (this character being mentioned when talking about Levels of Reality, the horizontal as a dimension of the commoners, philosophy and Possible intersections)! In "Dialogue with a topographer" the character's discourse represents an apparent plea for Unity: “- Please believe me - he said - we don't enjoy divorcing certain correlated notions: we have never insinuated between the river and the forest or between homes belonging to the same patronymic family, or between elements of a series, such as arithmetic numbers. [...] The falling leaf is still connected, sentimentally, to the branch from which it fell: I have never separated them" (Doinaş, 2000: 62-63). Arguments tend to keep the coherence and harmony of elements belonging to various fields: nature, science, interhuman relations. The topographer, symbol of total contradiction and falseness, declares himself a man of science, made whole through humanistic connotations: "It's true, I have 
mostly studied Trigonometry and Heterophysics; still, we know how much cruelty and cynicism hides behind the saying Divide et Impera..." (Doinaş, 2000: 63) The terrifying reality is that only the human being is subjected to separation (the border separates only the human). The prose illustrates the terror of the individual faced with an instrument of the absurd which does not separate the elements of the environment or creations of the human mind, but rather destroys the human being. The action of the aggressor, regardless of whether it represents an instrument of a totalitarian regime or another kind of society, produces suffering by dividing the whole.

A troubling play of perspectives is proposed by another story, "Two globes", in which the focus is threefold and constantly subjective. The three narrators are a commoner "Thin, tall, dark-haired, one metre eighty tall, weighing $75 \mathrm{~kg}$ " (Doinaş, 2000: 29), a tiny man "who stands no more than five centimetres tall, weighing just a few grammes" (Doinaş, 2000: 29) and the artist, bigger than the others (named so in the absence of concrete determinations), who is the creator of the two globes in which the other creatures live: "I managed to make a crystal globe with a tiny man inside, and insert it into a bigger globe which contains another man, slightly larger, identical to the first one" (Doinass, 2000: 33). The idea (colourfully expressed by one of the characters) is the existence of concentric, layered universes, just like the Russian dolls: "So, I live within something identical to myself, just as a circle rests within another larger circle. Could this be the higher step to perfection to which I am a part myself?" (Doinaş, 2000: 32-33). The privileged moment of discovery, certainly knowing that other horizons exist beyond your given world, is similar to the final revelation of supreme happiness: "I would like to tell you that what I'm feeling in such moments is called ecstasy. If I dared use such a language, maybe anachronistic but extremely true to the sensations I'm feeling, I would have to say that during these three days I was able to see God" (Doinaş, 2000: 33). There is an infinity of levels of knowledge though, and surprises are omnipresent, an aspect which is suggested by the open ending to the story, through the voice that expresses supreme lenience towards the agitated beings of the other dimensions "Interestingly enough, none has any clue about my existence" (Doinaş, 2000: 34), which inevitably leads the reader to ask 
Maria Chețan, Ştefan Augustin Doinaş and Basarab Nicolescu...

HSS, vol. IV, no. 2 (2015): 29-43

himself in which circle he would find himself.

The suggestion of a reality from another dimension is resumed in another prose, "The laughter", in which one of the characters experiences things that go beyond the ordinary level of perception and understanding: "How was I to believe in the existence of an invisible being who, from time to time, laughs Homerically above us?" (Doinaş, 2000: 41). The image of the distant and ironic puppeteer is completed by communicating, during privileged but random moments, between different dimensions: "It was a refreshing and impersonal laughter, coming from somewhere deep above, as if a skylight to nothingness had just opened" (Doinaş, 2000: 44).

"The $3^{\text {rd }}$ IAHMA Congress" is a story about the shapes that reality can take - "his colleagues were bringing feathers and horns as proof that these creatures give another dimension to the bland and trivial reality" (Doinaş, 2000: 79-80), about mystifying it, about misinterpreting the signs or deliberately supressing the mystery. The imaginary IAHMA (The International Association for Hunters of Mythical Animals) convincingly demonstrates that from the sublime to the ridiculous there is but a step. Falsifying reality can happen for various reasons, for vain material reasons, to ignorance or misunderstanding. The border between worlds is present, the hiatus is obvious; the common sense cannot accept certain unusual events and instead of merely acknowledging its existence, it tries to reduce them to something known or to transform the supernatural to a hunting trophy: hunters gathered in the clearing in the Silver Forrest (a reminiscence of Eminescu, expressing the unquantifiable ineffable) are desperately crying that the mythical animals are nowhere to be found: "Many of them now had eyes blurred with tears. What are they supposed to display on the walls of their great halls in their castles?" (Doinaş, 2000: 80) the purpose has become to kill everything that is different, the element that cannot be standardised "the secretary of the Prague association managed to take down a unicorn" (Doinaş, 2000: 80) or to isolate (creating a preservation for mythical beasts) - gestures which reveal a mind incapable of accepting anything out of the ordinary, cutting down the fantastic and reducing it to a bare minimum, stripped of everything beyond the comfort of common sense.

Another prose - "Plane existence" - a parabolic presentation of 
constrains and all kinds of aggressions, could very well illustrate the "reeducation" process of the communist years, levelling and the depersonalisation (through the sinister procedure of "reconditioning" with the help of the "Roller"). The story presents giant concrete, wood or wool cylinders which must roll over all human beings with the purpose of reducing them to two dimensions. The author's "double" language aims equally at the "court-oriented writers" (that would be so present in their own books in pink or green blotter paper), "the aesthetic of the portrait" which would revolutionise the expressiveness of the profile or the "deserving citizens" who might, depending on the services rendered to the regime, double or even triple their anatomical carton. The social registry is camouflaged in this prose beneath a story with unusual elements: "trained giraffes" will pick people up from the sidewalk, teaching them to walk again, "national kangaroos" will carry around the individuals incapable of adapting or the "human waste" will be used instead of statues.

Of a particular interest is the way to "visualize" the task at hand, the satire on the system being configured by the writer by referencing geometry elements: the goal is to eliminate the third dimension and to institute a plane existence for all individuals. This idea belongs to the "Inspector General on Space Matters", and it identifies another partition of the visual fields, reducing the living space, etc. The elimination of the moral dimension and the reduction of the individual to a deformed existence are associated with the exclusion of the third dimension: "A multitude of serious shortcomings, some enduring since Antiquity, could be definitively eradicated if people accepted to live a plane existence" (Doinaş, 2000: 45).

Scholarly developed spatial configurations, concentric universes, geometrical drawings and dimensional levels, reality branching out, odd temporal correspondences, reflections on the status of the individual and its links to the social or the divine, avatars of human beings, parallel universes, strange characters and a splendid incorporation of philosophical concepts in parabolic stories are merely some of the enticing aspects which Doinaş's prose offers readers as subjects to meditate upon. 


\section{References}

Doinaș, Şt. A. Year 38 (138). "Kilometre zero". The Family. $5^{\text {th }}$ edition. no. 5, 439.

Doinaș, Şt. A. "What is transdisciplinarity?", The Current. $4^{\text {th }}$ June 1998

Doinaș, Şt. A. T from Treasure. $21^{\text {st }}$ Century Cultural Foundation, 2000.

Doinaș, Şt. A. Poetry reading followed by Tragic and demonic, Romanian Book Publishing, 1980.

Nicolescu, B. Poetical theorems, Translated from French by L.M.Arcade, Prefaced by Michel Camus, Iasi: Junimea, 2007.

\section{Biographical note}

Maria Chețan is a teacher at the "Unirea" National College of Târgu-Mureș, Romania and has obtained her $\mathrm{PhD}$ in literature from the "Petru Maior" University in the same city. In the field of criticism and literary essays, she has published studies in Romanian and foreign publications, as well as a book about the literary stances in the works of Ştefan Aug. Doinaș. In the field of education, she has published several books as an author, co-author or coordinator of anthologies. 